\title{
LUPUS NEPHRITIS PREVALENCE AND COMPARISON OF CLINICAL/IMMUNOLOGICAL FINDINGS BETWEEN LUPUS PATIENTS WITH AND WITHOUT NEPHRITIS
}

Larissa Crysthine Aguiar Brasil ${ }^{1}$, Yuri Santana Pereira Dias ${ }^{1}$, Naryanna Renata Arantes de Morais ${ }^{1}$, Ana Carolina de Oliveira e Silva Montandon ${ }^{1}$, Jozelia Rêgo ${ }^{1}$, Nílzio Antônio da Silva ${ }^{1}$, Vitalina de Souza Barbosa ${ }^{1, *}$

1.Universidade Federal de Goiás, Goiânia (GO), Brazil.

*Corresponding author: vitalina.barbosa@gmail.com

\section{BACKGROUND}

Renal involvement is a common manifestation in systemic lupus erythematosus (SLE) occurring at any time and considered a predictor of poor prognosis. The aim of this study was to determine the prevalence of nephritis and to compare clinical and immunological findings among lupus patients with and without nephritis.

\section{METHODS}

A cross-sectional, retrospective, descriptive and observational study was carried out between January 2017 to May 2019. Seventy-seven medical records of patients with SLE were analyzed. Student's t-test for independent samples was used to compare quantitative variables and Pearson's chi-squared test or Fisher's exact test was used to compare qualitative variables. Values of $p \leq 0.05$ were considered statistically significant.

\section{RESULTS}

Seventy females and 7 males were analyzed. The prevalence of nephritis was $55.8 \%(n=43)$. The mean age at SLE onset and the mean disease duration were $42.1 \pm 12.0$ years old and $11.1 \pm 8.0$ years, respectively in patients without nephritis and $37.4 \pm 12.7$ years old and $11.1 \pm 8.0$ years, respectively in patients with nephritis. There was a predominance of females in both groups, $91.3 \%$ without nephritis and $90.7 \%$ with nephritis. There was no significant difference regarding age, sex and time since diagnosis between patients with or without nephritis. The most common symptoms were arthralgia ( $88.2 \%$ without nephritis vs. $88.4 \%$ with nephritis; $p=1.000$ ), arthritis (67.6\% without nephritis vs. $69.8 \%$ with nephritis; $p=0.842)$, photosensitivity $(73.5 \%$ without nephritis vs. $76.7 \%$ with nephritis; $p=0.745$ ), malar erythema (61.8\% without nephritis vs. $62.9 \%$ with nephritis; $p=0.926$ ) and alopecia ( $50.0 \%$ without nephritis vs. $55.8 \%$ with nephritis; $p=0.612$ ). There were statistically significant differences between patients with and without nephritis regarding the presence of systemic arterial hypertension (55.8\%. vs $23.5 \% ; p=0.004$ ). The most common laboratory findings were: ANA (97.1\% without nephritis vs. $95.1 \%$ with nephritis; $p=1.000$ ), anti-DNA (46.2\% without nephritis vs. $75 \%$ with nephritis; $p=0.017$ ) and low C3 (55.1\% without nephritis vs. $74.4 \%$ with nephritis; $p=0.139)$ and low $C 4$ (60.7\% without nephritis vs $71.1 \%$ with nephritis; $p=0.379$ ).

\section{CONCLUSION}

Systemic arterial hypertension and anti-DNA were prevalent manifestations in patients with lupus nephritis and should be closely monitored and treated, due to the increased risk of complications for this group of patients.

\section{KEYWORDS}

Systemic lupus erythematosus, Lupus nephritis, Renal involvement, SLE. 